\title{
Investigation on the microstructure, microhardness, and tribological behavior of AA1100-hBN surface composite
}

\author{
Premkumar R. ${ }^{1}$, Vignesh R. V. ${ }^{1}$, Padmanaban R. ${ }^{1}$, Govindaraju M. ${ }^{1}$, Santhi $R .{ }^{2}$ \\ ${ }^{1}$ Department of Mechanical Engineering, Amrita School of Engineering, Coimbatore, \\ Amrita Vishwa Vidyapeetham, India \\ 2 Department of Mathematics, Sri Ramakrishna Engineering College, Coimbatore, India \\ E-mail: r_vairavignesh@cb.amrita.edu
}

Aluminum alloy AA1100 has less wear resistance and mechanical properties than that of other aluminum alloys. This research work is on the fabrication of surface composites of AA1100 alloy by friction stir processing (FSP). The surface composites are fabricated by reinforcing $h B N$ (hexagonal Boron Nitride) in AA1100 alloy to improve the mechanical and tribological properties. The influence of process parameters, rotational speed (rpm), and transverse speed $(\mathrm{mm} / \mathrm{min})$ on the microstructural evolution and properties of the fabricated surface composites is investigated.

\section{INTRODUCTION}

Nowadays, research works are focused on the development of lightweight alloys to improve the efficiency of components. Aluminum and aluminum alloys are widely used in engineering components in the aerospace, aircraft, and industries because of their low density and cost. Aluminum alloys provide good corrosion resistance and strength comparable to steel. In aluminum alloys, alloying elements are added to achieve desired properties. Pure aluminum grades (1xxx series) exhibit comparatively less strength and wear resistance. However, they are extensively used in fin stock, heat exchanger fins, spun hollowware, dials and nameplates, decorative parts, giftware, cooking utensils, rivets and reflectors, and in sheet metal work.

AA1100 belong to the $1 \mathrm{xxx}$ series having less than $1 \%$ of alloying elements. It can be easily cold worked and has high electrical conductivity, high thermal conductivity, and good corrosion resistance. Conventionally, AA1100 alloy is employed for radiator components. The low strength and tribological properties have narrowed down the applications of AA1100 alloy. However, the properties of AA1100 alloy could be augmented by conventional/unique processing methodologies. Improving the properties would improvise the applications of AA1100 alloy in digital printing panel, architectural façade panels, decorative parts, giftware, cooking utensils, rivets and reflectors.

Surface modification methods like laser surface melting, physical vapor deposition, chemical vapor deposition, sputtering, plasma spray process, surface welding, and electrochemical deposition methods result majorly in intermetallic reactions and heterogeneous distribution of new phases. Compositing technologies provide excellent and unique properties to the desired base material through the addition of reinforcements. Friction stir processing (FSP) is a promising solid-state processing technology to fabricate composites with homogenous dispersion of reinforcements and without chemical reaction between the matrix and reinforcement. Besides, friction stir processing results in reduced or very less residual stress.

In FSP, the microstructure of the material is modified through severe plastic deformation and thermal effect (recovery and recrystallization). This deformation is achieved by inserting a non-consumable tool on the workpiece and rotating it at a certain speed. Frictional heat that is generated between the base material and rotating tool is the key factor for plastic deformation. The rotating tool is moved longitudinally along the workpiece that enables material flow with simultaneous recovery and recrystallization phenomenon.

Control of FSP process parameters ensures grain refinement, distribution of secondary phases (surface modification) or reinforcement particles (surface composites), and less residual stress $[1,3]$. Hence, the properties of friction stir processed material depend on parameters like rotation speed, traverse speed, the load applied on the workpiece through a rotating tool, tool tilt angle, shoulder diameter, pin profile [4-6], and the number of passes [7-9]. The friction stir processing improves the mechanical, tribological, and corrosion properties [10-12]. 
Researches are being carried out on fabricating composites of AA 1100 using various reinforcements like GYP [13], $\mathrm{TiB}_{2}$ [14], and $\mathrm{TiO}_{2}$ nanofibers [15]. Most of the research work on AA1100 based composites report improvement in hardness and tensile strength. However, a few research works are available on improving the tribological properties of AA1100 alloy. Hence a persistent research gap exists in the improvement of tribological properties of AA1100 alloy through surface compositing technique. AA1100 alloy reinforced with a reinforcement that has a simultaneous effect on reducing the wear rate and friction modification is seldom discussed in the open literature.

In this study AA1100-hBN (hexagonal Boron Nitride) composite was fabricated using FSP. Solid-state lubricant $\mathrm{hBN}$ was used to improve the tribological properties of AA1100 through FSP. Initially, the process window for FSP of AA1100 was determined by FSP surface modification trials (without reinforcements). Based on the macrostructure and microstructure analysis, the optimum process window was obtained. Then, surface composites were fabricated using the range of process parameters from the process window. Microstructure, microhardness, wear rate, and friction coefficient of the developed composites were investigated. A comprehensive analysis of the tribological properties was reported.

\section{MATERIALS AND METHODS}

\section{Materials}

Wrought AA1100 plate of thickness $4 \mathrm{~mm}$ with a purity of $99 \%$ is used in the study. The optical emission spectroscopy result, as given in Table 1, shows the conformity of received wrought AA1100 alloy to the standard composition of the alloy (standard IS19000). Hexagonal Boron Nitrid, a solid-state lubricant, with an average grain size of 40 to 60 microns was used as reinforcement.

\section{Friction stir processing}

Wrought AA1100 alloy was sheared to a size of $4 \times 50 \times 100 \mathrm{~mm}$ in a hydraulic shear-cutting machine. A square groove of dimension $1 \times 1 \times 80 \mathrm{~mm}$ was machined on the surface of the sheared plate (workpiece), which was filled with $\mathrm{hBN}$ powder to fabricate surface composite. FSP trials were carried out in the friction stir welding setup at Amrita Vishwa Vidyapeetham. FSP tool (EN32 Steel) of shoulder diameter of $18 \mathrm{~mm}$, pin diameter of $6 \mathrm{~mm}$, and pin height $3.5 \mathrm{~mm}$ was used for FSP trials.

FSP trials were carried out with a different combination of parameters like tool rotational speed, tra-

Tab. 1. Chemical properties of AA1100

\begin{tabular}{|l|c|c|c|c|c|c|c|c|c|}
\hline Elements & $\mathbf{A l}$ & $\mathbf{F e}$ & $\mathbf{S i}$ & $\mathbf{C u}$ & $\mathbf{M n}$ & $\mathbf{M g}$ & $\mathbf{C r}$ & $\mathbf{N i}$ & $\mathbf{Z n}$ \\
\hline Composition (wt. \%) & 99.2 & 0.373 & 0.131 & 0.025 & 0.02 & 0.026 & 0.02 & 0.03 & 0.025 \\
\hline Elements & $\mathbf{S n}$ & $\mathbf{T i}$ & $\mathbf{P b}$ & $\mathbf{C a}$ & $\mathbf{G a}$ & $\mathbf{S r}$ & $\mathbf{Z r}$ & $\mathbf{B i}$ & $\mathbf{C d}$ \\
\hline Composition (wt. \%) & 0.04 & 0.018 & 0.04 & 0.003 & 0.012 & 0.001 & 0.008 & 0.01 & 0.014 \\
\hline
\end{tabular}

Tab. 2. Experimental plan for FSP trials (Surface modification)

Tab. 3. Experimental plan for FSP trials (Surface composite)

\begin{tabular}{|c|c|c|c|}
\hline $\begin{array}{c}\text { Sl. } \\
\text { No. }\end{array}$ & $\begin{array}{c}\text { Rotational speed } \\
(\mathbf{r p m})\end{array}$ & $\begin{array}{c}\text { Traverse speed } \\
(\mathbf{m m} / \mathbf{m i n})\end{array}$ & $\begin{array}{c}\text { Specimen } \\
\text { code }\end{array}$ \\
\hline 1 & 400 & 20 & FSP-01 \\
\hline 2 & 400 & 40 & FSP-02 \\
\hline 3 & 400 & 60 & FSP-03 \\
\hline 4 & 600 & 20 & FSP-04 \\
\hline 5 & 600 & 40 & FSP-05 \\
\hline 6 & 600 & 60 & FSP-06 \\
\hline 7 & 800 & 20 & FSP-07 \\
\hline 8 & 800 & 40 & FSP-08 \\
\hline 9 & 800 & 60 & FSP-09 \\
\hline 10 & 1000 & 20 & FSP-10 \\
\hline 11 & 1000 & 40 & FSP-11 \\
\hline 12 & 1000 & 60 & FSP-12 \\
\hline
\end{tabular}

\begin{tabular}{|c|c|c|c|c|}
\hline $\begin{array}{c}\text { SI. } \\
\text { No }\end{array}$ & $\begin{array}{c}\text { Rotational } \\
\text { speed (rpm) }\end{array}$ & $\begin{array}{c}\text { Traverse speed } \\
(\mathbf{m m} / \mathbf{m i n})\end{array}$ & $\begin{array}{c}\text { No of } \\
\text { pass }\end{array}$ & $\begin{array}{c}\text { Specimen } \\
\text { code }\end{array}$ \\
\hline 1 & 400 & 20 & 1 & SC-01 \\
\hline 2 & 400 & 20 & 2 & SC-02 \\
\hline 3 & 400 & 40 & 1 & SC-03 \\
\hline 4 & 400 & 40 & 2 & SC-04 \\
\hline 5 & 400 & 60 & 1 & SC-05 \\
\hline 6 & 400 & 60 & 2 & SC-06 \\
\hline 7 & 600 & 40 & 1 & SC-07 \\
\hline 8 & 600 & 40 & 2 & SC-08 \\
\hline 9 & 600 & 60 & 1 & SC-09 \\
\hline 10 & 600 & 60 & 2 & SC-10 \\
\hline 11 & 800 & 60 & 1 & SC-11 \\
\hline 12 & 800 & 60 & 2 & SC-12 \\
\hline
\end{tabular}


verse speed, and the number of passes, based on the experimental plan shown in Tables 2 and 3. Three experimental trials were performed for each FSP trial. The sequence of experimental trials, as given in the experimental layout, were randomized in the course of experimentation. Based on the FSP trials, the optimum range for fabricating surface composites was determined.

\section{Macrostructure and Microstructure:}

Specimens were prepared by cutting the processed workpieces in the traverse direction. The specimens were prepared and were polished for macrostructure/microstructure analysis inline with standard ASTM E3-11. The polished surface of the specimen was etched for 15 seconds and rinsed with cold water. Macrostructure was examined after etching with Keller's reagent that was prepared by mixing $2.5 \mathrm{ml}$ nitric acid, $1.5 \mathrm{ml}$ of hydrochloric acid, $1 \mathrm{ml}$ of hydrofluoric acid with $95 \mathrm{ml}$ of distilled $\mathrm{H}_{2} \mathrm{O}$. The macrostructure of the specimens was captured using a high-resolution camera. The etchant for microstructural analysis was prepared by mixing $25 \mathrm{ml}$ methanol, $25 \mathrm{ml}$ hydrochloric acid, $25 \mathrm{ml}$ nitric acid, and $1 \mathrm{ml}$ of hydrofluoric acid. The polished surface of the specimens was etched for 10 seconds and rinsed in cold water. Microstructures of the specimens were captured using an optical microscope (Make: Carl Zeiss, Model: Axiovert 25).

\section{Grain size and orientation analysis}

Electron Back Scattered Diffraction (EBSD) was used to analyze the grain size and grain orientation of the surface composite. The specimen was cut to a size of $4 \times 10 \times 10 \mathrm{~mm}$. Specimens were polished electrolytically and were subjected to analysis.

\section{Microhardness}

The specimens for microhardness analysis were prepared from the composite and base material as per the standard ASTM E3-11. For the composite specimen, the indentations were made along the friction stir zone. A normal load of $100 \mathrm{gf}$ was applied for 10 s to measure the microhardness. Mitutoyo Vicker's microhardness tester was used to measure the microhardness of the specimens. The average microhardness of the specimen (10 spots) is reported in the manuscript.

\section{Tribology test}

Specimens were prepared as per standard ASTM E3-11. Dry sliding wear was performed using a pinon-disc tribometer. The dry-sliding characteristics were evaluated at a sliding velocity of $0.5 \mathrm{~m} / \mathrm{s}$ for a period of 1200 seconds under a load of $14.715 \mathrm{~N}$ load $(1.5 \mathrm{~kg})$.
The counter disc was made of EN 32 steel (hardness of 65HR).

\section{Characterization - morphology and elemental analysis}

A high-resolution scanning electron microscope (Make: Zeiss Sigma) was used to analyze the surface morphology of the specimen. An energy-dispersive X-ray spectroscope (Make: Bruker) was used to analyze the elemental composition and elemental distribution in the worn region of the specimens.

\section{RESULTS AND DISCUSSIONS}

\section{Macrostructure analysis of surface-modified specimens}

The surface modification trials were performed in-line with the experimental plan shown in Table 2. The macrostructure of the surface-modified specimens is shown in Table 4. A combination of TRS and TTS resulted in macro-structural defects like a wormhole, small voids, lack of fill, and galling. The specimen FSP-04 processed at TRS of $600 \mathrm{rpm}$ and TTS of $20 \mathrm{~mm} / \mathrm{min}$ showed material lack of fill defect. This was attributed to the improper material flow in the processed zone. Higher rotational speed caused enough heat generation in the stir zone. However, lesser traverse speed caused a lack of material flow. The specimen FSP-07 processed at $800 \mathrm{rpm}$ and $20 \mathrm{~mm} / \mathrm{min}$ showed small voids and dents. An increase in rotational speed with the same traverse speed created excess heat generation and resulted in smaller type voids. The specimen FSP-08 processed at $800 \mathrm{rpm}$ and $40 \mathrm{~mm} / \mathrm{min}$ resulted in material lack of fill. An increase in traverse speed from $20 \mathrm{~mm} / \mathrm{min}$ to $40 \mathrm{~mm} / \mathrm{min}$ at a rotational speed of $800 \mathrm{rpm}$ resulted in turbulence at the stir zone.

The specimens FSP-10, FSP-11, and FSP-12 processed at a TRS of $1000 \mathrm{rpm}$ and TTS of $20 \mathrm{~mm} / \mathrm{min}$, $40 \mathrm{~mm} / \mathrm{min}$, and $60 \mathrm{~mm} / \mathrm{min}$ respectively had groove defects. Higher rotation speed resulted in more heat generation, which in turn severely plasticized and obstructed material flow. FSP-01, FSP-02, FSP-03, FSP-05, FSP-06, FSP-09 had no visual defects. In these parameters, heat generation and material flow were perfectly managed. Based on the above results, the process window determined for the fabrication of surface composites is as follows:

TRS: $400 \mathrm{rpm}$ to $800 \mathrm{rpm}$

TTS: $20 \mathrm{~mm} / \mathrm{min}$ to $60 \mathrm{~mm} / \mathrm{min}$ 
Tab. 4. Defect analysis of surface modified specimens

\begin{tabular}{|c|c|c|c|c|c|c|c|}
\hline $\begin{array}{l}\text { SI. } \\
\text { No. }\end{array}$ & $\begin{array}{c}\text { Specimen } \\
\text { code }\end{array}$ & Macrostructure & Defects & $\begin{array}{l}\text { SI. } \\
\text { No. }\end{array}$ & $\begin{array}{c}\text { Specimen } \\
\text { code }\end{array}$ & Macrostructure & Defects \\
\hline 1 & FSP-01 & & No visual defect & 7 & FSP-07 & & Micro voids \\
\hline 2 & FSP-02 & & No visual defect & 8 & FSP-08 & & Lack of fill \\
\hline 3 & FSP-03 & & No visual defect & 9 & FSP-09 & & No visual defect \\
\hline 4 & FSP-04 & & Lack of fill & 10 & FSP-10 & & Groove \\
\hline 5 & FSP-05 & & No visual defect & 11 & FSP-11 & & Groove \\
\hline 6 & FSP-06 & & No visual defect & 12 & FSP-12 & & Groove \\
\hline
\end{tabular}

\section{Macrostructure analysis of surface composites}

Based on the process window, the experimental plan for surface compositing of specimens was devised. The surface composites were fabricated as per the experimental plan in Table 3. The fabricated surface com- posite specimens are shown in Table 5. No defects were observed on the specimens SC01, SC02, SC03, SC04, SC07, SC08, SC09, SC10, SC11, and SC12, except for the specimens SC-05 and SC-06. Composite specimens SC-05 and SC-06 were processed at TRS of $400 \mathrm{rpm}$, 
TTS of $60 \mathrm{~mm} / \mathrm{min}$ followed by one pass, and two-pass respectively. The second pass was performed at $100 \%$ overlapping. The specimen that was subjected to twopass had no defect, whereas and the specimen that was subjected to one-pass had a surface galling defect.

\section{Microstructure}

The microstructure analysis revealed that the surface composites had a refined microstructure. The typical microstructure of the surface composite specimen SC-02 in the stir zone with delineated grain boundaries is shown in Figure 1a. The Fe content in the base material was $0.373 \%$ (as shown in Table 1). The formation of $\mathrm{Al}-\mathrm{Fe}$ intermetallic phases or segregation of $\mathrm{Fe}$ in the $\alpha$-Al phase was not observed. The dynamic recovery and recrystallization phenomenon resulted in refined grains. Besides, the pinning effect of $\mathrm{hBN}$ particles refined the microstructure of the surface composited specimens. Figure $1 \mathrm{~b}$ shows the EBSD result of the surface composite specimen SC-02 that was processed at $400 \mathrm{rpm}$, $20 \mathrm{~mm} / \mathrm{min}$, and two-pass. The average grain size observed was $2.6 \mu \mathrm{m}$ with a standard deviation of 3.3. The grain size was 32 times lesser than that of the material's grain size $(84 \mu \mathrm{m})$. A more preferred orientation was observed in the grains, as shown in Figure 1c.
The fraction of grains with a misorientation angle was less in the composite specimen SC-02. The elemental composition of the composite specimen SC-02 is shown in Figure 2a. Significant peaks were detected for Al, B, $\mathrm{N}, \mathrm{C}, \mathrm{O}$, and $\mathrm{Si}$. The composition analysis confirms the presence of $\mathrm{hBN}$ reinforcement particles in the surface composite specimen SC-02.

Figure $2 \mathrm{~b}$ shows the selected area for the elemental mapping of SC-02. The consolidated elemental mapping of SC-02 is shown in Figure 2c. The elemental map of $\mathrm{Al}, \mathrm{O}, \mathrm{Si}$, and $\mathrm{C}$ is shown in Figure $2 \mathrm{~d}$. The elemental map of $\mathrm{B}$ and $\mathrm{N}$ confirms the presence of $\mathrm{hBN}$ on the surface of the AA1100.

\section{Microhardness}

The microhardness of the base material was $28 \mathrm{HV}$. The microhardness of the defect-free friction stir processed specimens, surface composite specimens fabricated by single pass ( $\mathrm{SC}-\mathrm{I}$ ) and double pass (SC - II) is shown in the Figure 3. The microhardness of FSPed specimens varied between $32 \mathrm{HV}$ and $36 \mathrm{HV}$. The surface composite specimens fabricated by single pass had microhardness between $32.92 \mathrm{HV}$ and $33.87 \mathrm{HV}$. And, the surface composite specimens fabricated by double-pass had microhardness between $32.2 \mathrm{HV}$ and

Tab. 5. Defect analysis in the fabricated surface composite specimen

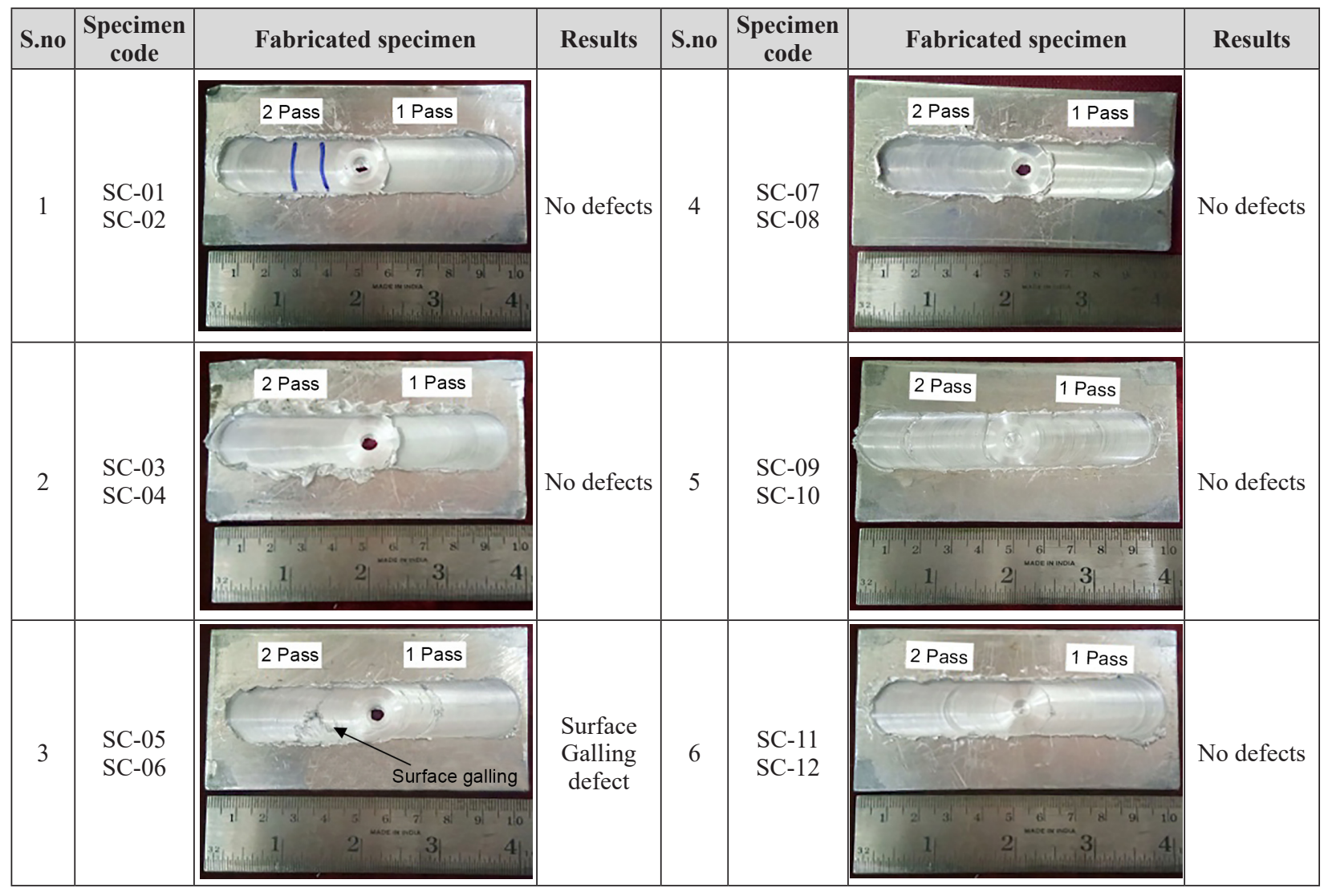




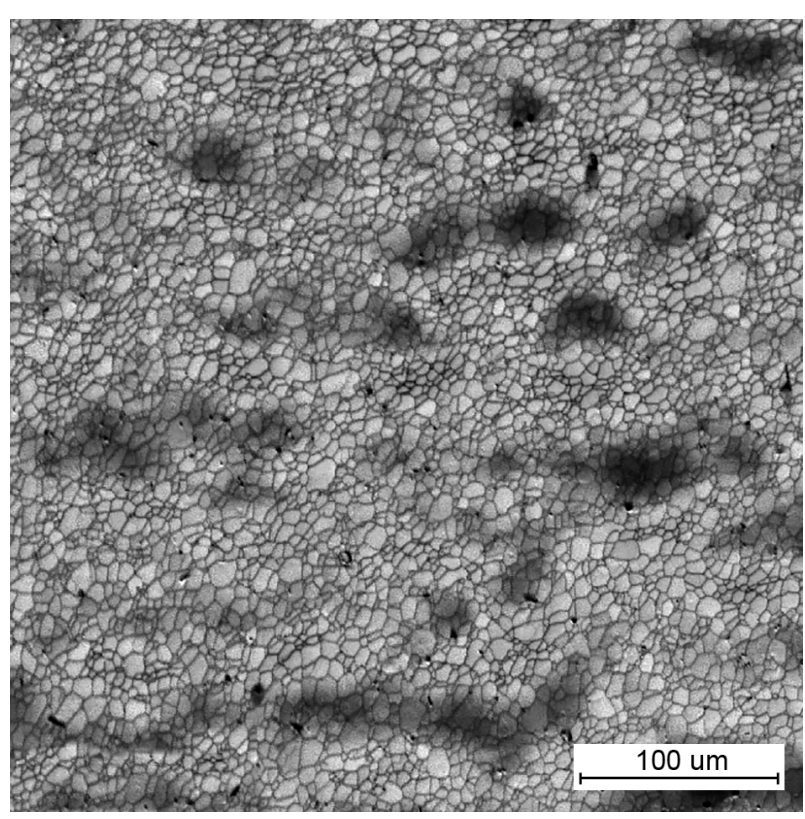

a)

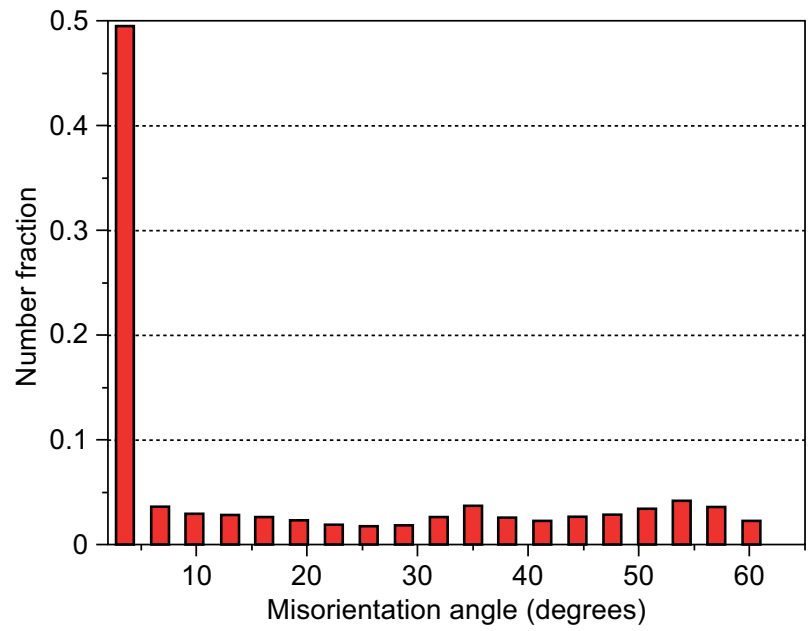

c)

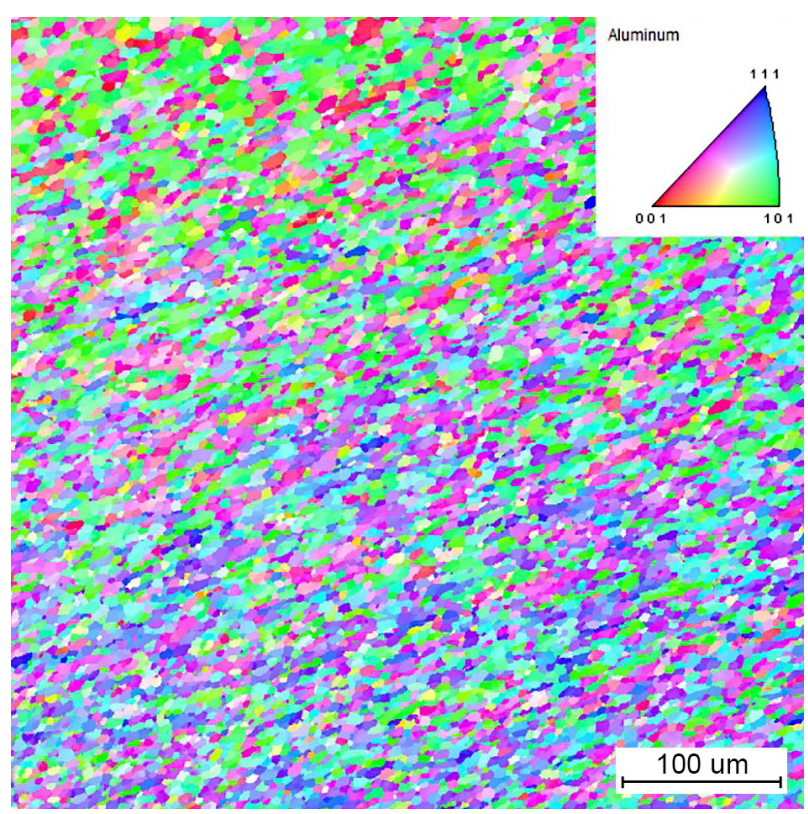

b)

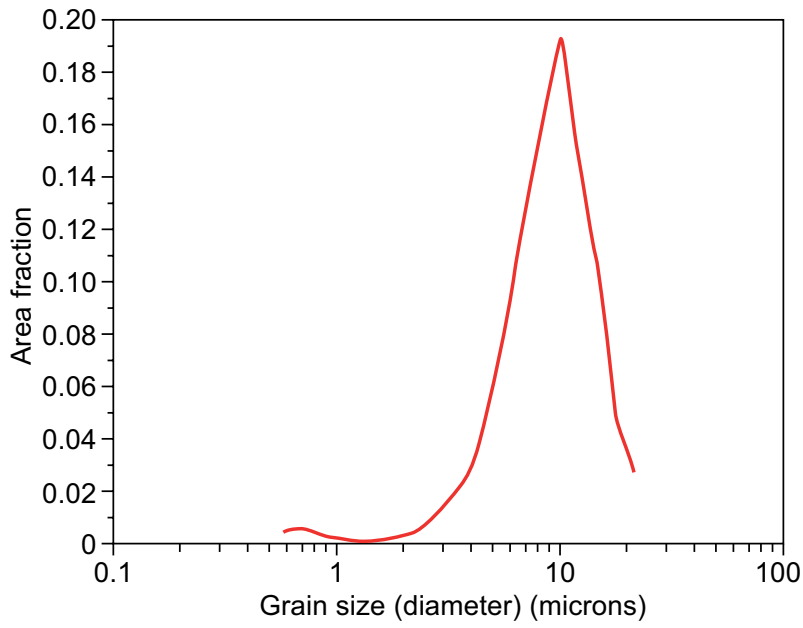

d)

Fig. 1. Microstructure of the specimen SC-02 (a), grain orientation in the specimen SC-02 (b), misorientation angle (c), grain size of SC-02 (d)

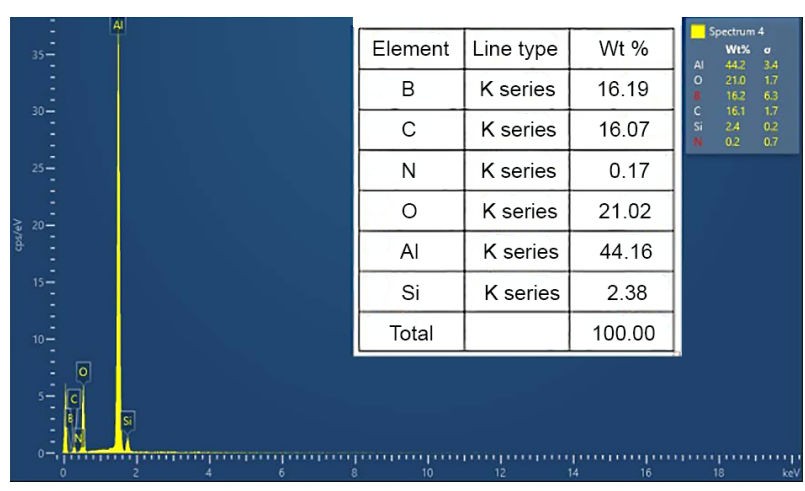

a)

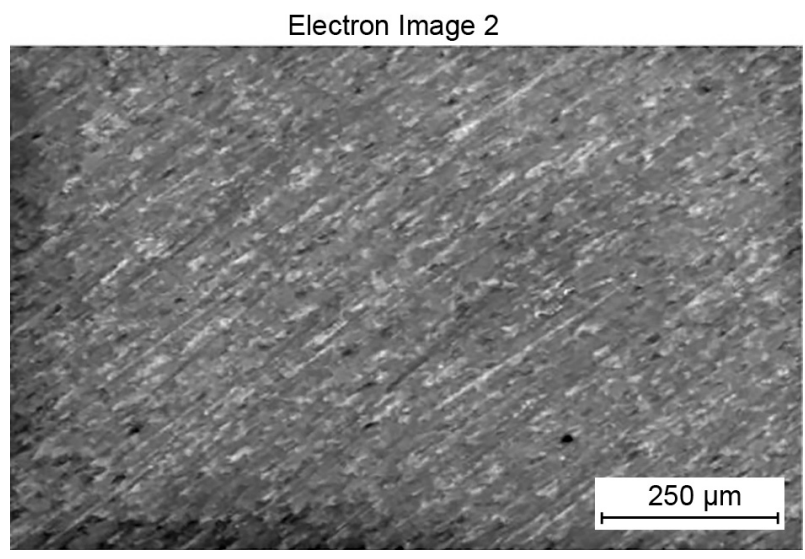

b)

Fig. 2. Elemental composition analysis of the specimen SC-02: a) EDS spectrum; b) selected area (Continue on next page) 


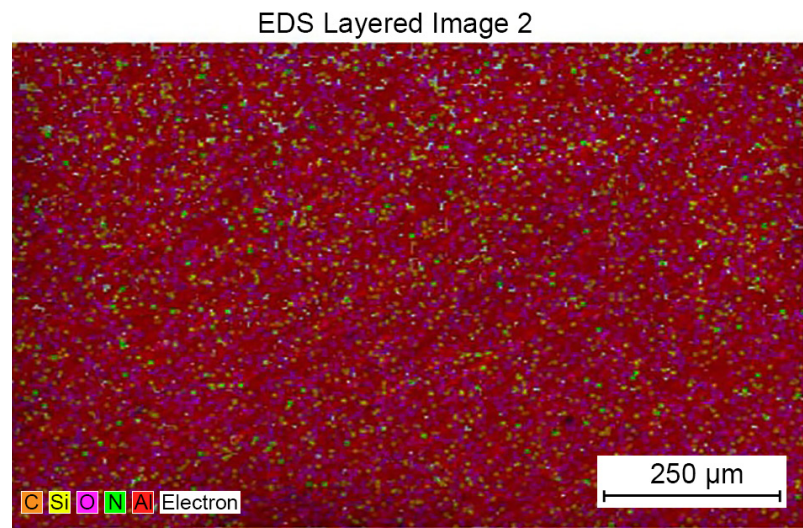

c)

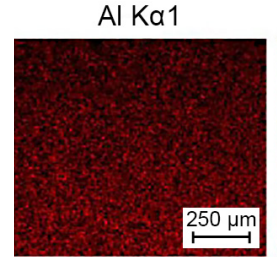

C Ka1_2

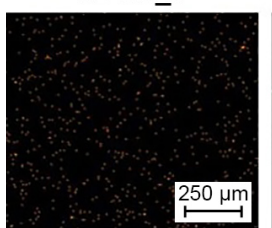

$\mathrm{OKa} 1$

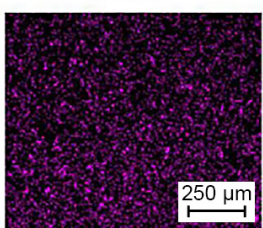

NKa1_2

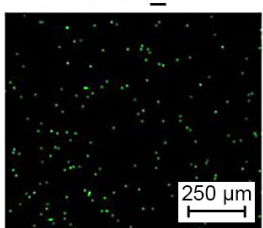

d)
Si Ka1

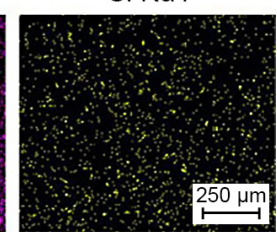

B Ka1_2

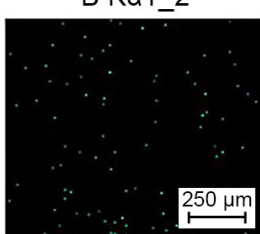

$250 \mu \mathrm{m}$

Fig. 2. Elemental composition analysis of the specimen SC-02: c) consolidated elemental map; d) individual elemental map of $\mathrm{Al}, \mathrm{O}, \mathrm{Si}, \mathrm{C}, \mathrm{N}$, and $\mathrm{B}$

$35 \mathrm{HV}$. The results indicate that the surface composite specimens (single pass and double pass) exhibited lower hardness than that of the FSPed specimen. This indicates that the reinforcement particle (hBN) has not significantly contributed to the improvement in microhardness of AA1100 alloy. In addition, the surface composite specimens fabricated by double-pass had higher hardness, compared to the surface composite

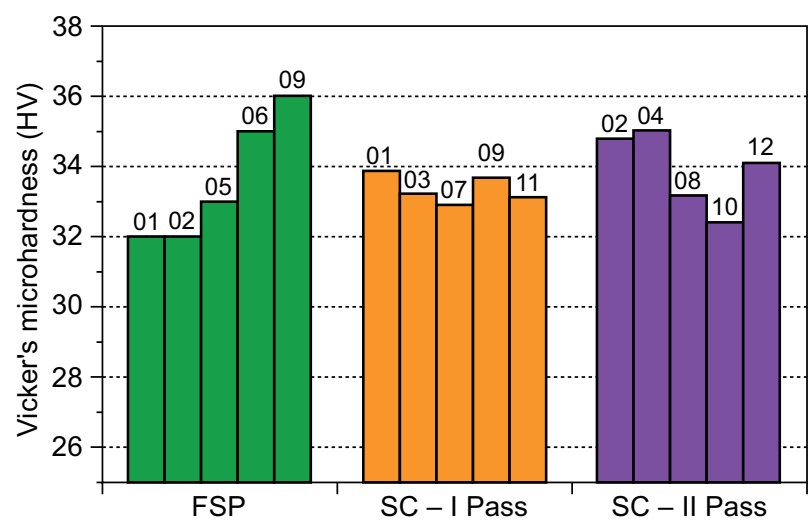

Fig. 3. Microhardness of the specimens (specimens with microstructural defects were not evaluated)

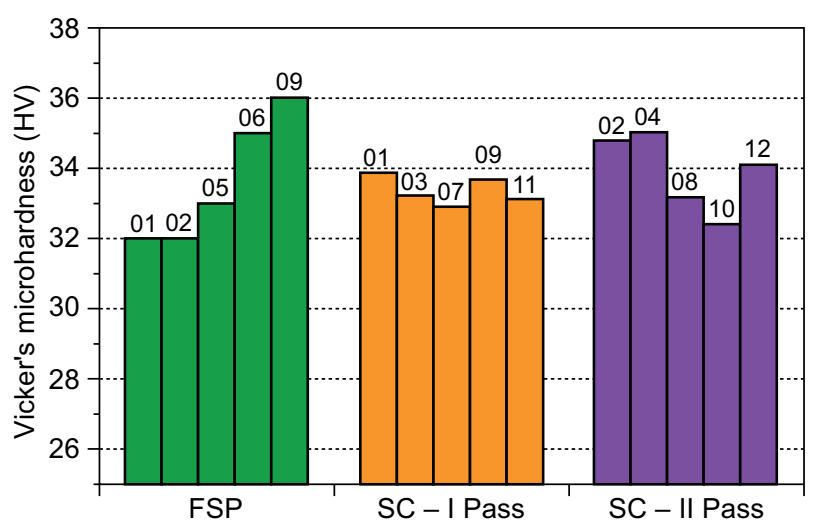

Fig. 4. Wear rate of the specimens

Koroze a ochrana materiálu 65(1) 1-11 (2021)

specimens fabricated by single-pass. This in-turn explicit that refinement of grains and fine-dispersion of $\mathrm{hBN}$ particles in the surface composite fabricated by double pass, augments the microhardness. Similar trend was observed between the specimens SC-01 and SC-02, SC03 and SC-04, SC-07 and SC-08, SC-11 and SC- 12. However, the specimens SC-09 and SC-10 deviated from this trend. Besides, the variation in microhardness between the specimens was minimal (less than 5\%).

\section{Wear rate}

Figure 4 shows the wear rate of the base material, FSPed specimen, and the composite specimens processed by single pass, and double pass. The wear rate of the base material AA1100 alloy was $3.397 \times 10^{-07} \mathrm{~g} / \mathrm{Nm}$. The wear rate of the FSPed specimens was between $1.9254 \times 10^{-07} \mathrm{~g} / \mathrm{Nm}$ and $4.077 \times 10^{-07} \mathrm{~g} / \mathrm{Nm}$. The surface composite specimens processed by single pass had wear rate between $1.359 \times 10^{-07} \mathrm{~g} / \mathrm{Nm}$ and $3.3979 \times 10^{-07} \mathrm{~g} / \mathrm{Nm}$. And the surface composite specimens fabricated by double pass had wear rate between $1.1326 \times 10^{-07} \mathrm{~g} / \mathrm{Nm}$ and $3.1714 \times 10^{-07} \mathrm{~g} / \mathrm{Nm}$. This shows that the wear rate of the composite material was lesser than that of the friction stir processed specimens. The double-pass fabricated surface composite specimens showed lesser wear rate than that of the single-pass fabricated surface composite. The second pass (100\% overlap) resulted in homogenous dispersion of $\mathrm{hBN}$ which in turn improved the wear resistance.

Among the tested specimens, the specimen SC-02 processed at $400 \mathrm{rpm}$ and $20 \mathrm{~mm} / \mathrm{min}$ followed by two passes showed the least wear rate and SC-10 processed at $600 \mathrm{rpm}, 60 \mathrm{~mm} / \mathrm{min}$ followed by one pass showed the highest wear rate. The wear rate also followed the same pattern as microhardness. Similar trend was observed between the specimens SC-01 and SC-02, SC03 and SC-04, SC-07 and SC-08, SC-09 and SC-10, SC-11 and SC-12. 


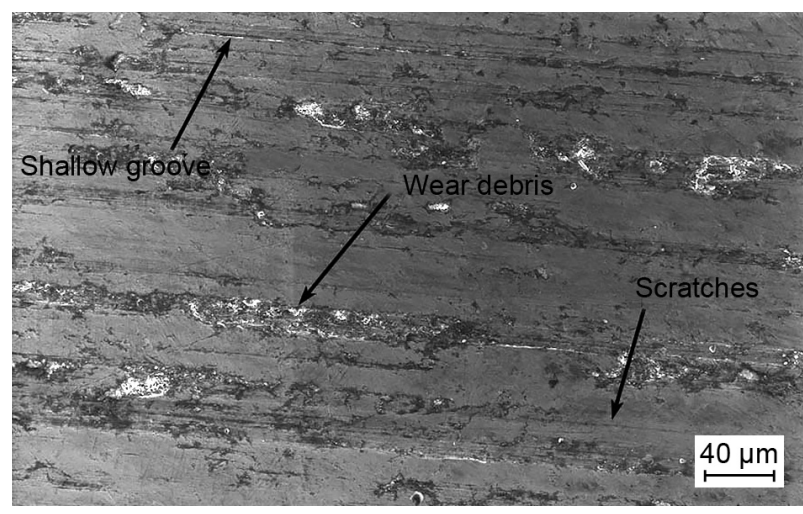

a)

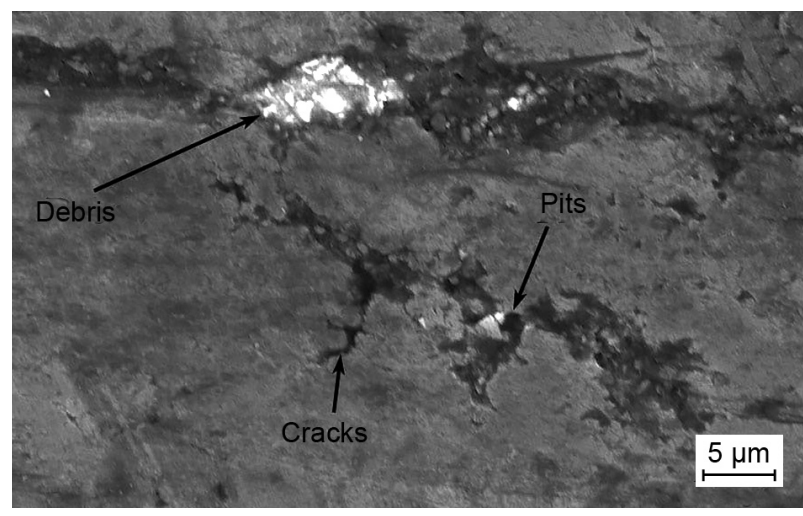

C)

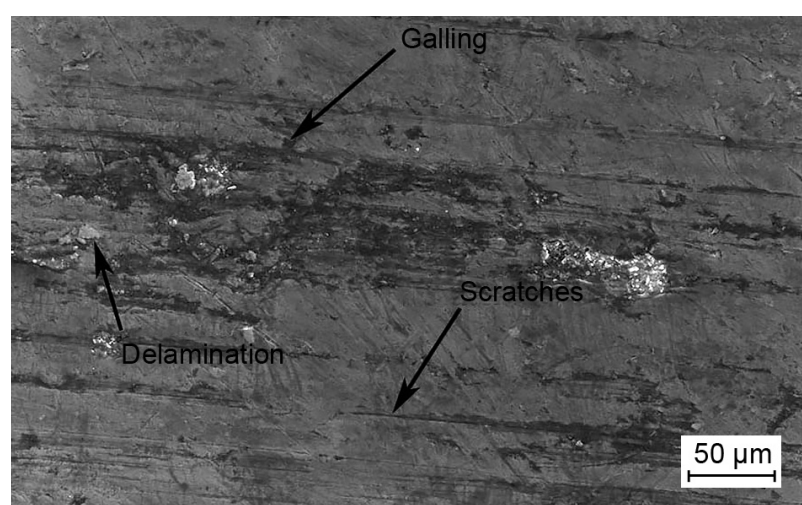

b)

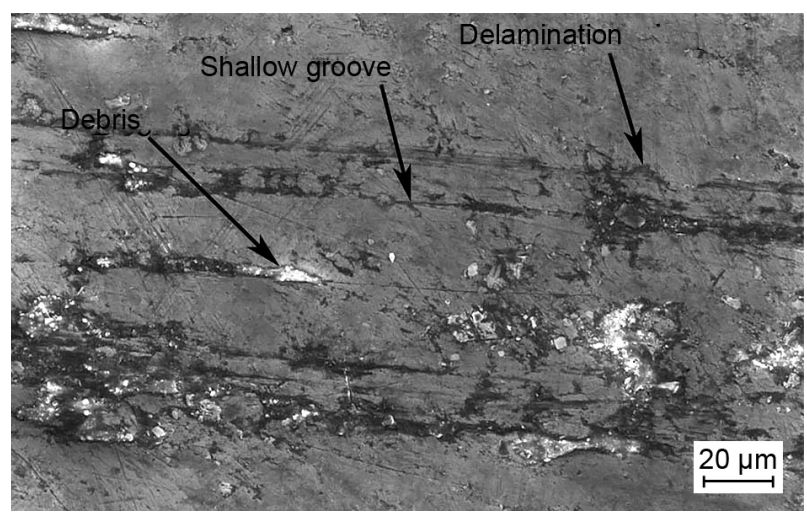

d)

Fig. 5. Surface morphology of SC-02 at magnification of a) $250 \times$; b) $500 \times$; c) $2000 \times$; d) $500 \times$

\section{Worn surface morphology}

Figure 5 shows the worn surface morphology of the specimen SC-02 that exhibited the least wear rate. Figure 5a shows the shallow grooves, wear debris and scratches; Figure 5b shows galling, delamination and scratches; Figure 5c shows debris, cracks and pits; Figure 5d shows debris, shallow groove, delamination. cumulatively, the features confirm that the specimen was worn by adhesive wear mechanism. The relative motion of the specimen with the counter disc resulted minimal plastic deformation and wear debris. Hence, the specimen had the least material removal rate in the course of wear test. This in turn attributed to the least wear rate.

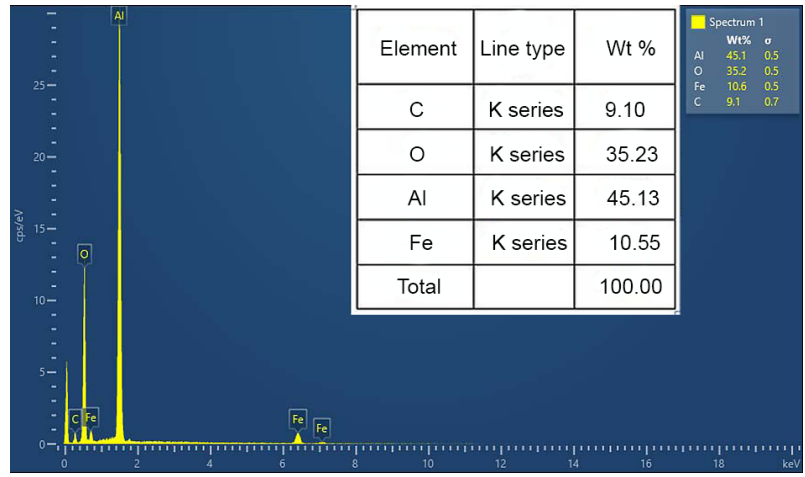

Fig. 6. Elemental composition of worn SC-02
The elemental composition analysis was performed on the specimen SC-02 after wear test to confirm the nature of wear mechanism. The peaks corresponding to elements $\mathrm{Al}, \mathrm{Fe}, \mathrm{C}$, and $\mathrm{O}$ was observed, as shown in Figure 6 . The presence of high concentration of $\mathrm{O}$ is an indicative of oxidation of the surface in the course of wear test.

The results of elemental mapping analysis is presented in Figure 7. Figures $7 \mathrm{a}$ and $7 \mathrm{~b}$ shows the selected area and consolidated elemental map of the specimen SC-02 after wear test. The individual elemental maps for the elements $\mathrm{Al}, \mathrm{O}, \mathrm{C}, \mathrm{Fe}, \mathrm{C}$, and $\mathrm{Si}$ is shown in Figure 7c. The presence of $\mathrm{O}$ is an indicative of oxidation of the surface in the course of wear test. Figure 8 shows the worn surface morphology of the specimen SC-10 that exhibited more wear rate. Figure 8a shows deep groove and wear debris; Figure $8 \mathrm{~b}$ shows spalling, pits, and arc crater; Figure 8c shows pits, scratches, and scuffing; Figure 8d debris, spalling, delamination and cracks. Hence, the worn surface morphology features confirm that the specimen was worn by abrasive wear mechanism. The relative motion of the specimen with the counter disc resulted maximum plastic deformation and wear debris. Hence, the specimen had the most material removal rate in the course of wear test. This in turn attributed to more wear rate. 


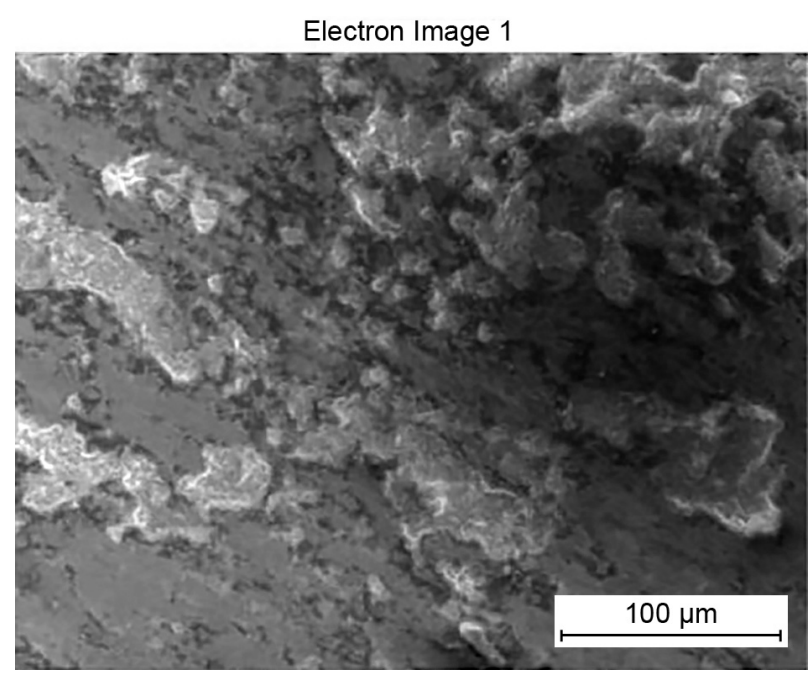

a)
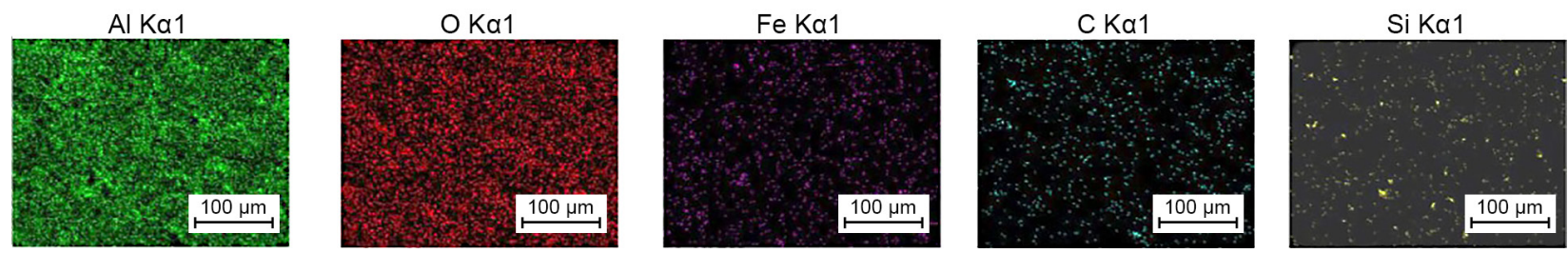

c)

EDS Layered Image 1

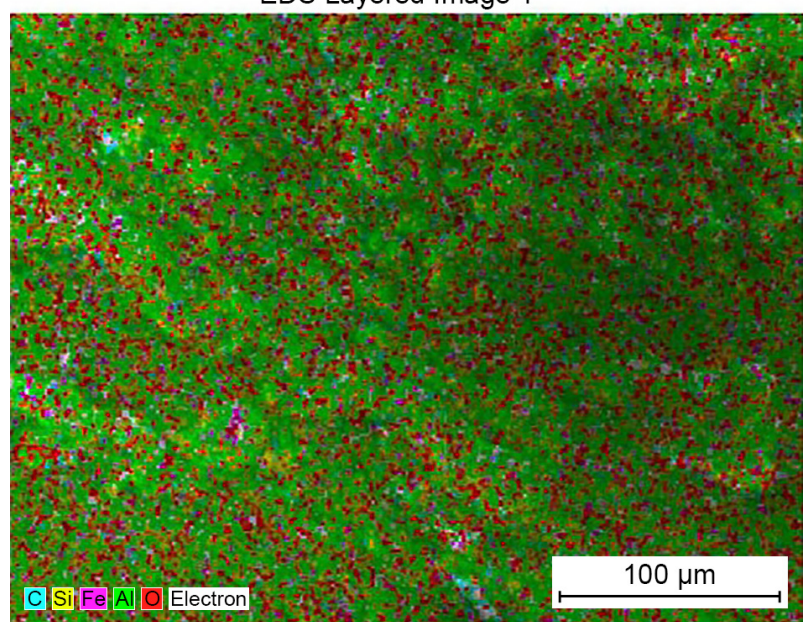

b)

Fig. 7. Elemental mapping analysis: a) selected area for analysis; b) consolidated elemental map; c) individual elemental map of $\mathrm{Al}, \mathrm{O}, \mathrm{Fe}, \mathrm{C}$, and $\mathrm{Si}$

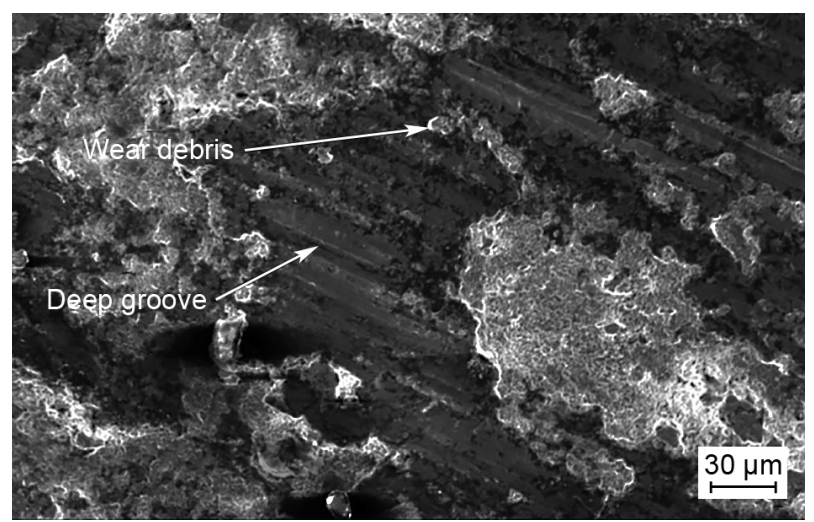

a)

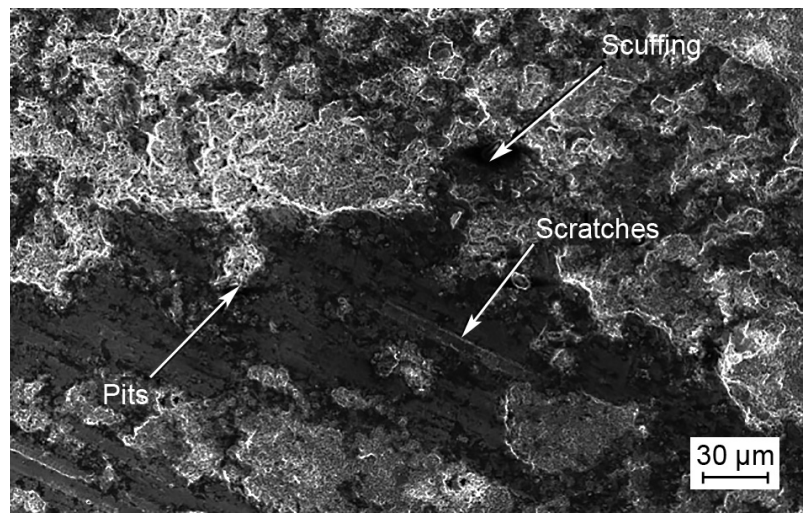

c)

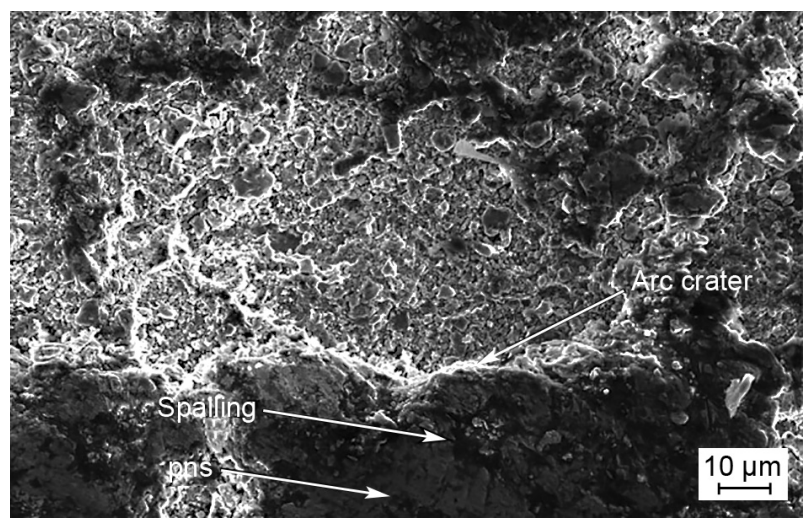

b)

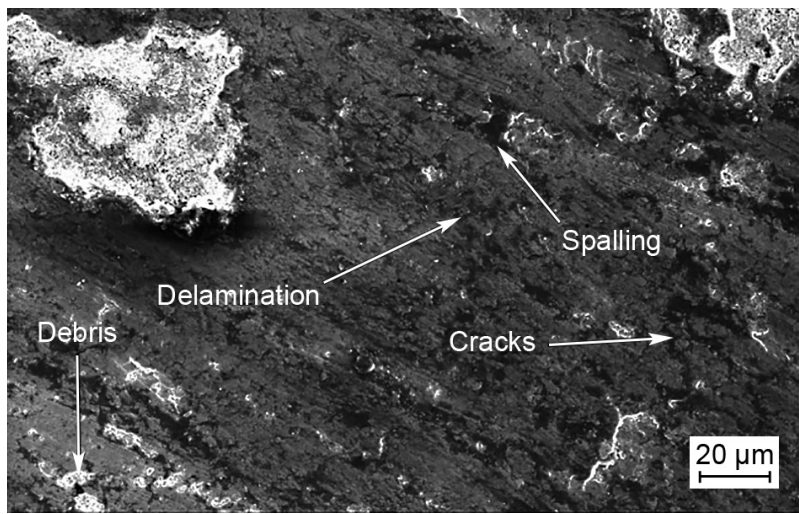

d)

Fig. 8. Surface morphology of SC-10 at magnification of a) $300 \times$; b) $750 \times$; c) $300 \times$; d) $500 \times$ 


\section{CONCLUSION}

Friction stir processing was performed by varying the tool rotation speed and tool traverse speeds on AA1100 alloy plate (surface modification and surface compositing). The microstructure, microhardness and wear rate of the specimens were analyzed. The results demonstrated the following:

- AA1100 alloy processed at $600 \mathrm{rpm}$ followed by tool rotation speed of $20 \mathrm{~mm} / \mathrm{min}$ and two pass $(100 \%$ overlapping) had minimal defect in the stir zone with refined grains and fine dispersion of $\mathrm{hBN}$ reinforcement particles.

- The microhardness of most of the friction stir processed specimens was higher than that of the base material. The maximum microhardness was observed in the specimen FSP-09.

- The wear resistance of FSPed specimens was higher than that of the base material. Surface composite specimen that were processed with two pass had better wear resistance than that of the surface composite specimen processed with one pass.

\section{REFERENCES}

1. Mishra, R.S., Ma, Z.Y., Charit, I.: Friction stir processing: a novel technique for fabrication of surface composite. Mater. Sci. Eng. A 2003, 341, 307-310. http://dx.doi. org/10.1016/S0921-5093(02)00199-5

2. Pantelis, D., Tissandier, A., Manolatos, P., Ponthiaux, P.: Formation of wear resistant Al-SiC surface composite by laser melt-particle injection process. Mater. Sci. Tech. 1995, 11, 299-303. http://dx.doi.org/10.1179/mst.1995.11.3.299

3. Ni, D.R., Wang, J.J., Zhou, Z.N., Ma, Z.Y.: Fabrication and mechanical properties of bulk NiTip/Al composites prepared by friction stir processing. J. Alloy Compd. 2014, 586, 368-374. http://dx.doi.org/10.1016/j.jallcom.2013.10.013

4. Dolatkhah, A., Golbabaei, P., Givi, M.K.B., Molaiekiya, F., 2012. Investigating effects of process parameters on Microstructural and mechanical properties of A15052/SiC metal matrix composite fabricated via friction stir processing. Mater. Design 2012, 37, 458-464. http://dx.doi. org/10.1016/j.matdes.2011.09.035

5. Khayyamin, D., Mostafapour, A., Keshmiri, R.: The effect of pro-cess parameters on microstructural characteristics of $\mathrm{AZ} 91 / \mathrm{SiO}_{2}$ com-posite fabricated by FSP. Mater. Sci. Eng. A 2013, 559, 217-221. http://dx.doi.org/10.1016/j. msea.2012.08.084

6. Mishra, R.S., Ma, Z.Y. Friction stir welding and processing. Mater. Sci. Eng. 2005, R50, 1-78. http://dx.doi. org/10.1016/j.mser.2005.07.001

7. Zohoor, M., Besharati Givi, M.K., Salami, P.: Effects of processing parameters on fabrication of $\mathrm{Al}-\mathrm{Mg} / \mathrm{Cu}$ composites via friction stir processing. Mater. Design 2012, 39, 358-365, http://dx.doi.org/10.1016/j.matdes.2012.02.042

8. Bauri, R., Yadav, D., Suhas, G. Effect of friction stir processing (FSP) on microstructure and properties of Al-TiC in situ composite. Mater. Sci. Eng. A 2011, 528, 4732-4739, http://dx.doi.org/10.1016/j.msea.2011.02.085

9. R. Vaira Vignesh, R. Padmanaban: Modelling tensile strength of friction stir welded Aluminium Alloy 1100 using Fuzzy logic. $11^{\text {th }}$ International Conference on Intelligent Systems and Control (ISCO) 2017. https://www. sciencedirect.com/science/article/pii/S2214785318311416

10. R. Vaira Vignesh and R. Padmanaban. Influence of friction stir processing parameters on the wear resistance of aluminium alloy AA5083. Materials Today: Proceedings 2018, 5, 7437-7446. https://www.sciencedirect.com/ science/article/pii/S2214785317326858

11. Vaira Vignesh Ramalingam, Padmanaban Ramasamy and Madhav Datta. Microstructure, hardness and corrosion behaviour of friction-stir processed AA5083. AntiCorrosion Methods and Materials 2019, 66 (6), 791-801. https://www.emerald.com/insight/content/doi/10.1108/ ACMM-07-2017-1816/full/html

12. R. Vaira Vignesh, R. Padmanaban, M. Govindaraju and G. Suganya Priyadharshini., 2019. Mechanical properties and corrosion behaviour of AZ91D-HAP surface composites fabricated by friction stir processing. Materials Research Express 2019, 6 (8), 085401. https://iopscience.iop.org/ article/10.1088/2053-1591/ab1ded/meta

13. Romeo Sephyrin Fono-Tamo., Esther Titilayo Akinlabi., Jen Tien-Chien., Kazeem Oladele Sanusi. Microstructural Investigation Of GYP/Al Surface Composites Fabricated By Friction Stir Processing. IEEE 10th International Conference on Mechanical and Intelligent Manufacturing Technologies (ICMIMT 2019), https://ieeexplore.ieee.org/ document $/ 8712052$

14. K.L. Tee, L. Lu, M.O. Lai. Wear performance of insitu Al-TiB composite. Wear 2000, 240 (1-2), 59 -64. https://www.sciencedirect.com/science/article/abs/pii/ S0043164800003379

15. Lifeng Zhang., Ramya Chandrasekar., Jane Y. Howe., Michael K. West., Nyle E. Hedin., William J. Arbegast., and Hao Fong: A Metal Matrix Composite Prepared from Electrospun $\mathrm{TiO}_{2}$ Nanofibers and an Al 1100 Alloy via Friction Stir Processing. Applied Materials and Interfaces 2009, 1 (5), 987-991. https://www.researchgate.net/publication $/ 42805360$

16. Devinder Yadav., Ranjit Bauri: Effect of friction stir processing on microstructure and mechanical properties of aluminium. Materials Science and Engineering A 2012, 539, 85-92. https://www.researchgate.net/publication/ 257336926

17. H.S. Grewal., H.S. Arora, H. Singh., A. Agrawal: Surface modification of hydroturbine steel using friction stir processing. Applied Surface Science 2013, 268, 547-555. https://www.sciencedirect.com/science/article/abs/pii/ S0169433213000238

18. X.C. Liu., Y.F. Sun., Y. Morisada., H. Fujii: Dynamics of rotational flow in friction stir welding of aluminium alloys. Journal of Materials Processing Technology 2017, 252. https://www.researchgate.net/publication/320667111

19. S. Selvakumar, I., Dinaharan, R., Palanivel. B., Ganesh Babu: Characterization of molybdenum particles reinforced Al6082 aluminum matrix composites with improved ductility produced using friction stir processing. Materials Characterization 2017, 125, 13-22. https://www. sciencedirect.com/science/article/abs/pii/S10445803163 06945 
20. Morteza Shamanian., Hossein Mostaan., Mehdi Safari., Jerzy A. Szpunar: Friction stir modifications of GTA 7075T6 Al alloy weld joints: EBSD study and microstructural evolutions. Archives of Civil and Mechanical Engineering 2017, 17, 574-585. https://www.sciencedirect.com/science/ article/abs/pii/S1644966517300110

21. Devinder Yadav, Ranjit Bauri: Processing, microstructure and mechanical properties of nickel particles embedded aluminium matrix composite. Materials Science and Engineering A 2011, 528, 1326-1333. https://www.sciencedirect. com/science/article/abs/pii/S0921509310012001

22. Parviz Asadi, Ghader Faraji., Mohammad K. Besharati: Producing of AZ91/SiC composite by friction stir processing (FSP). Int. J. Adv. Manuf. Technol. 2010, 51, 247-260. https://www.researchgate.net/publication/226868014

23. M. Azizieh., A.H. Kokabi., P. Abachi: Effect of rotational speed and probe profile on microstructure and hardness of $\mathrm{AZ31} / \mathrm{Al}_{2} \mathrm{O}_{3}$ nanocomposites fabricated by friction stir processing. Materials and Design 2011, 32, 2034-2041. https://www.sciencedirect.com/science/article/pii/S026130 6910006813

24. V. Balasubramanian: Relationship between base metal properties and friction stir welding process parameters. Materials Science and Engineering A 2008, 480, 397-403. https://www.sciencedirect.com/science/article/pii/S0261 306910001949
25. Mohsen Barmouz., Mohammad Kazem Besharati Givi., Javad Seyfi: On the role of processing parameters in producing $\mathrm{Cu} / \mathrm{SiC}$ metal matrix composites via friction stir processing: Investigating microstructure, microhardness, wear and tensile behavior. Materials Characterization 2011, 62, 108-117. https://www.sciencedirect.com/science/ article/abs/pii/S1044580310003232

26. Adem Kurt., Ilyas Uygu., Eren Cete. Surface modification of aluminium by friction stir processing. Journal of Materials Processing Technology 2011, 211, 313-317. https://www. researchgate.net/publication/229231990

27. Mohammad Ali Moghaddas., Seyed Farshid KashaniBozorg., 2012. Effects of thermal conditions on microstructure in nano composite of $\mathrm{Al} / \mathrm{Si} 3 \mathrm{~N} 4$ produced by friction stir processing. Materials Science and Engineering A 2013, 559, 187-193. https://www.sciencedirect.com/ science/article/abs/pii/S092150931201194X.

28. M. Mosallaee., M. Dehghan: Improvement of Structural and Mechanical Properties of Al-1100 Alloy via Friction Stir Processing. ASM International 2014, 1059-9495. https:// link.springer.com/article/10.1007/s11665-014-1155-9

29. M. Salehi, M. Saadatmand, J., Aghazadeh Mohandesi: Optimization of process parameters for producing AA6061/ $\mathrm{SiC}$ nanocomposites by friction stir processing. Trans. Nonferrous Met. Soc. China 2012, 22, 1055-1063. https:// www.sciencedirect.com/science/article/abs/pii/S10036326 11612831 